\title{
Shear peeling of steel plates adhesively bonded to the sides of reinforced concrete beams
}

\section{S. Mohamed Ali, D. J. Oehlers and M. A. Bradford}

R. A. Barnes and G. C. Mays, Cranfield University (Royal Military College of Science)

The authors are to be congratulated on the development of design procedures for predicting shear peeling resistance.

The authors have conducted all of their experimental beam tests at one shear span $(a)$ to depth $(d)$ ratio. Shear of reinforced concrete beams is a notoriously complicated area ${ }^{24}$ and it is known that different failure mechanisms predominate at different values of shear span to depth ratio. ${ }^{25}$ At the shear span to depth ratio used (3.6), a mode of failure known as diagonal-tension failure predominates, which is initiated by a flexure-shear crack. Other failure modes include: shear compression failure $(2 \cdot 5>a / d>1)$ and deep beam failure mode $(a / d<1)$, which are not initiated by a flexure-shear crack. As the design procedure relies upon the characteristics of crack formation, it is likely to only apply to load scenarios within a defined range of $a / d$ values.

The authors state that the only variables that can affect the stress distribution shown in Fig. 14 are plate thickness, depth of beam, length of plate and Young's modulus of both the concrete and the steel plate. However, both adhesive thickness and modulus have been found by ourselves and others ${ }^{26,27}$ to affect the stress distribution, the implication being that the use of a different adhesive and adhesive thickness to that used by the authors may affect the coefficients $k_{1}$ and $k_{2}$.

The possible applications illustrated in Fig. 1 show plated reinforced concrete T-beams, whereas the experimental programme and the shear plating model presented both assume a rectangular section. In T-beams there will be a concentration of stress at the web-flange junction where flat side-plates cannot be bonded. Hence, we have found that the use of side-plates for strengthening T-beams is likely to be less effective than their corresponding use on rectangular beams. ${ }^{27}$ On the other hand, the possible reduced effectiveness of side-plates when bonded to the compression zone, as reported by the authors, will become less of an issue in T-beams.

\section{Authors' reply}

We would like to thank the contributors for their interesting and in particular their constructive comments.

With regard to their second paragraph on the limitations of the technique to certain bands of span to depth ratios $a / d$, we agree that predicting the shear strength of reinforced concrete (RC) beams is a notoriously complicated area. As stated in the paper, we have used, as the basis of our research, the technique developed by Zhang, ${ }^{18}$ under Professor Nielsen's supervision, for predicting the shear strength of RC beams and slabs without shear reinforcement. This procedure is unique as it requires two parameters for predicting the shear strength-that is, the shear load to cause cracking and the shear strength after cracking. Furthermore, not only does it give the shear strength but it also predicts the position of the critical diagonal crack, albeit in an idealised form, which is essential for predicting the shear peeling capacity of plated beams. It is also worth noting that Zhang's approach has enormous potential as it can also be used for continuous beams, simply supported beams, prestressed beams, those subjected to uniformly distributed loads as well as concentrated loads as used in the paper. This technique has been verified experimentally by Zhang, from the results of 280 beam tests in which $a / d$ ranged from about 0.6 to 7 , and was found to give good correlation for $a / d$ ratios greater than 2 . Hence, Zhang stated that it is applicable to normal shear span ratios. For $a / d$ values less than 2 , Zhang found that the technique gave a safe design. Having adapted Zhang's approach for plated beams, those bounds that govern Zhang's approach will also apply to plated beams. Hence, we agree with your statement that these design rules are only applicable to a defined range of $a / d$ values which we believe is for $a / d>2$ but safe for values less than 2 . As you have commented, the plated beam tests used a fixed value of $a / d=3 \cdot 6$. This was fixed so that the plate positions could be varied to validate our adaptation of Zhang's approach for plated beams. They were not used to confirm Zhang's theory as he had already done this with 180 tests. However, our unplated beam tests showed remarkably good correlation with Zhang's predicted strengths.

With regard to your third paragraph on the $k_{1}$ and $k_{2}$ factors, theoretically predicting the axial peeling strength for tests such as those shown in Fig. 14 is an incredibly difficult problem. To the best of our knowledge, a mathematical model has, as yet, not been developed that allows for the interaction between the plate, adhesive and concrete, and that also allows for the gradual propagation of the debonding crack prior to failure. Hence, at the moment, the safest approach is to determine the axial peeling resistance directly from tests. The analysis we used in Fig. 14 is a simple and logical approach that gave 
remarkably good results as shown in Fig. 15, probably because, as you have inferred, the adhesive properties for these tests were constant and hence $k_{1}$ and $k_{2}$ were constant for these tests. Hence, we agree with the contributors that the adhesive thickness and modulus will affect the stress distribution as they and others have found. We would like to make the comment that as far as axial peeling is concerned, and where peeling occurs adjacent to the adhesive layer, the properties of the adhesive may be important. However, for tension face plated beams where flexural peeling and shear peeling invariably occur at the level of the tension reinforcement, then we would suggest that the adhesive properties are of minor importance because of the large thickness of concrete that separates the adhesive layer from the peeling crack. This has been shown by tests to be true. ${ }^{28}$

With regard to the T-beams mentioned in the fourth paragraph, it may be worth noting that we have also tested beams with plates adhesively bonded to their compression faces ${ }^{29,30}$ and have developed design rules for predicting the enhanced shear capacities. These compression face plated beams also debonded between the plate and the concrete in a fashion similar to that which you have described as stress concentrations between the flange and the web. We feel that the flanges of T-beams can only improve the resistance to the formation of the critical diagonal crack by resisting some of the vertical shear, and hence using the shear peeling resistance of the web of the T- beam will give a safe design in positive regions and probably an accurate design in negative regions.

\section{REFERENCES}

24. REgAn P. E. Research on shear: a benefit to humanity or a waste of time? The Structural Engineer, 1994, 72, No. 18, Oct., 304-308.

25. Kong F. K. and Evans R. H. Reinforced and Prestressed Concrete. Chapman and Hall, London, 1996.

26. BRESSON J. Nouvelle recherches et applications concernant l'utilisation des collages dans les structures. Béton plaqué. 1971. Annales de l'Institut Technique due Batiment et des Travaux Publics, Suppl. No. 278, Paris, 1971, 23-54.

27. BARNES R. A. Strengthening Reinforced Concrete Beams in Shear by the Use of Externally Bonded Steel Plates. PhD thesis, Cranfield University (Royal Military College of Science), 2000.

28. Oehlers D. J. and Ali M. Prediction of the maximum plate end stresses of FRP strengthened beams (Discussion). Magazine of Concrete Research, 1996, Dec., 343-351. (Published in Magazine of Concrete Research, 1996, 50, No. 1, Mar., 91-92.)

29. Mohamed Ali M. S., Oehlers D. J. and Bradford M. A. Peeling of plates bonded to the compression faces of RC beams. (Submitted August 2000.)

30. Mohamed Ali M. S. Peeling of Plates Adhesively Bonded to Reinforced Concrete Beams. PhD thesis, Adelaide University, 2000. 